\title{
Interaction of Dietary Cholesterol and Triglycerides in the Regulation of Hepatic Low Density Lipoprotein Transport in the Hamster
}

\author{
David K. Spady and John M. Dietschy \\ Department of Internal Medicine, The University of Texas Health Science Center at Dallas, \\ Southwestern Medical School, Dallas, Texas 75235-9030
}

\begin{abstract}
These studies report the effects of dietary cholesterol and triglyceride on rates of receptor-dependent and receptor-independent LDL transport in the liver of the hamster. In animals fed diets enriched with $0.1,0.25$, or $1 \%$ cholesterol for 1 mo, receptor-dependent LDL transport in the liver was suppressed by 43,63 , and $77 \%$, respectively, and there were reciprocal changes in plasma LDL-cholesterol concentrations. In addition, dietary triglycerides modified the effect of dietary cholesterol on hepatic LDL transport and plasma LDL concentrations so that at each level of cholesterol intake, polyunsaturated triglycerides diminished and saturated triglycerides accentuated the effect of dietary cholesterol. When animals were raised from weaning on diets containing small amounts of cholesterol, the decline in receptor-dependent LDL transport was nearly abolished by the addition of polyunsaturated or monounsaturated triglycerides, but was markedly augmented by the addition of saturated lipids. When animals raised on diets containing cholesterol and saturated triglycerides were returned to the low cholesterol, low triglyceride control diet, hepatic receptor-dependent LDL transport and plasma LDLcholesterol concentrations returned essentially to normal within 2 wk. Neither receptor-independent LDL transport nor the receptor-dependent uptake of asialofetuin was significantly altered by dietary cholesterol or triglyceride suggesting that the effect of these lipids on hepatic LDL receptor activity was specific and not due to a generalized alteration in the physiochemical properties of hepatic membranes. These studies demonstrate the important role of saturated triglycerides in augmenting the effect of cholesterol in suppressing hepatic LDL receptor activity and elevating $\mathrm{LDL}$-cholesterol levels.
\end{abstract}

\section{Introduction}

It has long been recognized that the substitution of polyunsaturated fat for saturated triglycerides in the diet results in a reduction in plasma cholesterol levels (1-4). Although the mechanism(s) responsible for this effect remains poorly understood, the relationship between various dietary lipids and plasma cholesterol levels in man has been studied in considerable detail (5-9). From these studies it appears that the magni-

Address reprint requests to Dr. Spady, Department of Internal Medicine, University of Texas Health Science Center at Dallas, 5323 Harry Hines Boulevard, Dallas, TX 75235-0930.

Received for publication 27 February 1987 and in revised form 30 July 1987.

J. Clin. Invest.

(C) The American Society for Clinical Investigation, Inc.

$0021-9738 / 88 / 02 / 0300 / 10 \quad \$ 2.00$

Volume 81, February 1988, 300-309 tude of the change in plasma cholesterol levels that can be achieved is dependent upon the ratio of polyunsaturated to saturated fatty acids in the diet. Furthermore, saturated fatty acids are approximately twice as active in raising plasma cholesterol levels as are polyunsaturated fatty acids in lowering them. The differential effects of polyunsaturated and saturated fatty acids on plasma cholesterol levels also appear to be magnified by dietary cholesterol (6).

Although it has been suggested that the decline in plasma cholesterol concentration produced by polyunsaturated fatty acids is related to an increase in fecal sterol excretion, the specific reason why fatty acids regulate plasma lipoproteincholesterol levels is not known. A number of mechanisms have been proposed including alterations in (a) the absorption of cholesterol from the small intestine, $(b)$ rates of de novo cholesterol synthesis, $(c)$ the distribution of cholesterol between plasma and various extrahepatic pools, $(d)$ the cholesterol content of VLDL and LDL, and $(e)$ the rates of synthesis or catabolism of plasma lipoproteins. Little direct evidence exists, however, to support any of these mechanisms. For example, it is not even clear what the effect of dietary triglycerides is on the synthesis and degradation of LDL-cholesterol. Whereas some investigators have reported that the increase in plasma LDL levels produced by feeding saturated fat is accompanied by a fall in the fractional catabolic rate $(F C R)^{1}(10)$, others have found little or no change in this parameter $(11,12)$. Furthermore, since most LDL is cleared from the plasma via receptor-dependent transport, it is difficult to interpret a change in the FCR for this lipoprotein under conditions where the plasma LDL-cholesterol concentration has also changed (13, 14). Thus, on the basis of currently available data it is not possible to determine whether the changes in plasma cholesterol levels brought about by triglyceride feeding result from alterations in the rate of receptor-dependent LDL degradation or the rate of synthesis of LDL particles.

The hamster has proved to be a good model in which to study these regulatory mechanisms since its concentration of plasma LDL-cholesterol responds to changes in dietary lipid intake in a manner that is essentially identical to that seen in man (15). Furthermore, the kinetics of LDL-cholesterol production and degradation have been worked out in detail in this species (13) so that it is possible, in quantitative terms, to identify the reason why a particular dietary or pharmacological manipulation results in a change in the steady state plasma LDL-cholesterol concentration. Using this model we recently reported that saturated triglycerides, but not polyunsaturated triglycerides, suppressed receptor-dependent LDL transport in

1. Abbreviations used in this paper: FCR, fractional catabolic rate; $J_{\mathrm{d}}$, receptor-dependent rate; $J_{\mathrm{i}}$, receptor-independent rate; $J^{\mathrm{m}}$, maximal transport velocity; $J_{t}$, production rate; methyl-hLDL, reductively methylated LDL of human origin. 
the liver of hamsters that were also receiving small amounts of dietary cholesterol (15). Such alterations in hepatic LDL receptor activity will significantly affect circulating LDL-cholesterol levels since $\sim 75 \%$ of LDL turnover is mediated by LDL receptors (16-18) and $\sim 85 \%$ of this receptor-dependent LDL transport is found in the liver of all species for which data are available (19-21). The present studies were therefore undertaken in this species $(a)$ to examine in detail the time and dose dependency of suppression of hepatic LDL transport by dietary cholesterol and triglycerides; $(b)$ to determine if the dietary suppression of receptor-dependent LDL transport in the liver is reversible; and $(c)$ to define the relationship between changes in receptor-dependent LDL transport and other metabolic events within the liver cell.

\section{Methods}

Animals and diet. Male Golden Syrian hamsters (Charles River Lakeview, Newfield, NJ) were housed in colony cages and subjected to light cycling for at least $3 \mathrm{wk}$ before use in specific experiments. The control diet used in these studies was ground Wayne Lab Blox (Allied Mills, Chicago, IL), which contained $0.23 \mathrm{mg} / \mathrm{g}$ of cholesterol as determined by gas-liquid chromatography. The total fat content of this diet was $5 \%$ and the fatty acid profile, as determined by gas-liquid chromatography of the methyl esters, was $14 \%$ of the fatty acid 16:0, 5\% 18:0, 27\% 18:1, $46 \% 18: 2$, and $6 \% 18: 3$. The experimental diets were prepared by adding varying amounts of cholesterol and/or triglyceride to this control diet. In those diets containing only cholesterol, the sterol was first dissolved in warm ethanol and mixed with the ground food following which the solvent was evaporated. In those diets also containing triglyceride, the cholesterol was first dissolved in the oil being added to the food. In all cases the diets were subjected to prolonged mixing using a mechanical food blender. The triglycerides used in these studies included safflower oil (iodine value of 140-150), olive oil (iodine value of 79-90), hydrogenated coconut oil (iodine value of $<4$ ) and tripalmitin (iodine value of $<4$ ). When the fatty acid methyl esters of these triglycerides were analyzed by gas-liquid chromatography, safflower oil contained $79 \%$ of the $18: 2$ fatty acid, olive oil contained $65 \% 18: 1$ and coconut oil contained $>90 \%$ satrated fatty acids of varying chain length. All diets were fed ad lib. and all experiments were carried out during the mid-dark phase of the light cycle.

Lipoprotein preparations. Hamster and human LDL was isolated from plasma by preparative ultracentrifugation in the density range of 1.020 to $1.055 \mathrm{~g} / \mathrm{ml}$ and labeled with either $\left[{ }^{125} \mathrm{I}\right]$ tyramine cellobiose (22) or ${ }^{131} \mathrm{I}$ using the iodine monochloride method (23). Both hamster and human LDL in this density range contained almost exclusively apoprotein $B_{100}$ on polyacrylamide gels. The whole-animal turnover of each LDL preparation was identical regardless of whether it was labeled with [ $\left.{ }^{125} \mathrm{I}\right]$ tyramine cellobiose or ${ }^{131} \mathrm{I}$ alone (unpublished observations from this laboratory). The human $\mathrm{LDL}$ was also subjected to reductive methylation (methyl-hLDL) to fully block its interaction with the LDL receptor $(20,24)$. Thus, the $\left[{ }^{125}\right.$ I] tyramine cellobiose-labeled homologous hamster LDL was used to quantitate the rate of total LDL transport by the liver while the similarly labeled methyl-hLDL was utilized to measure the receptor-independent component of this transport process $(13,20)$. All lipoproteins were used within $24 \mathrm{~h}$ of preparation and were filtered through a $0.45-\mu \mathrm{m}$ Millipore filter immediately before use.

Determination of hepatic LDL uptake rates in vivo. Rates of hepatic LDL clearance were determined using a primed-continuous infusion of $\left[{ }^{125}\right.$ I] tyramine cellobiose-labeled LDL $(19,20)$. The radioactivity present in the priming dose relative to the radioactivity subsequently infused each hour was adjusted so as to maintain a constant specific activity of the LDL in plasma throughout the experimental period. The infusions of $\left[{ }^{125} I\right]$ tyramine cellobiose-labeled LDL were continued for $4 \mathrm{~h}$ at which time each animal was administered a bolus of ${ }^{131}$ I-labeled
LDL and killed 10 min later by exsanguination through the abdominal aorta. Samples of various organs were quickly rinsed and weighed and, along with aliquots of plasma, were assayed for radioactivity. The tissue space achieved by LDL at $10 \mathrm{~min}\left({ }^{131} \mathrm{I} \mathrm{dpm}\right.$ per $\mathrm{g}$ of tissue divided by the ${ }^{131} \mathrm{I} \mathrm{dpm}$ per $\mu \mathrm{l}$ of plasma) and at $4 \mathrm{~h}$ (the ${ }^{125} \mathrm{I} \mathrm{dpm}$ per $\mathrm{g}$ of tissue divided by the ${ }^{125} \mathrm{I}$ dpm per $\mu \mathrm{l}$ of plasma) was then calculated and has the units of microliters per gram (25). The increase in tissue space with time represents the clearance of LDL by the liver and was expressed as the microliter of plasma cleared of its LDL content per hour per gram of liver. This clearance rate was also multiplied by the plasma LDL-cholesterol concentration to give the absolute mass of LDL-cholesterol taken up per hour by each gram of liver (20).

Determination of hepatic sterol synthesis rates in vivo. As previously described $(26,27)$, animals were killed $1 \mathrm{~h}$ after the intravenous administration of $\left[{ }^{3} \mathrm{H}\right]$ water $(\sim 50 \mathrm{mCi})$. Rates of sterol synthesis were expressed as the nanomoles of $\left[{ }^{3} \mathrm{H}\right]$ water incorporated into digitonin precipitable sterols per hour per gram of liver.

Analytic procedures. Plasma LDL-cholesterol concentrations were determined by simultaneously centrifuging plasma at densities of 1.020 and $1.063 \mathrm{~g} / \mathrm{ml}$. The cholesterol content of the top one-third of each tube, as well as the total plasma cholesterol concentration, was assayed colorimetrically as previously described (28). The hepatic content of free and esterified cholesterol was measured using silicic acid/celite columns (28).

Calculations. Where appropriate, data are presented as mean values $\pm 1 \mathrm{SEM}$. In order to relate changes in hepatic LDL clearance to changes in LDL receptor number or, more appropriately, to the maximal transport velocity $\left(J^{m}\right)$ for the receptor-dependent system, the experimentally determined clearance rates were superimposed upon the kinetic curves defining the rates of LDL uptake in the liver as a function of the plasma LDL-cholesterol concentration in control hamsters. These curves were constructed for the liver (e.g., Fig. 1) using the following, previously published transport parameters: $P^{*}-0.080 \pm 0.025 \mu \mathrm{g} / \mathrm{h}$ per $\mathrm{g}$ per $\mathrm{mg} / \mathrm{dl} ; K_{\mathrm{m}}-108.7 \pm 5.7 \mathrm{mg} / \mathrm{dl}$; and $J^{\mathrm{m}}-126.0 \pm 9.6 \mu \mathrm{g} / \mathrm{h}$ per $\mathrm{g}(13)$. Utilizing these curves, LDL clearance rates measured at any plasma LDL-cholesterol concentration could be converted directly to $J^{\mathrm{m}}$ values and these values are presented as a percentage of the appropriate control values in each experiment.

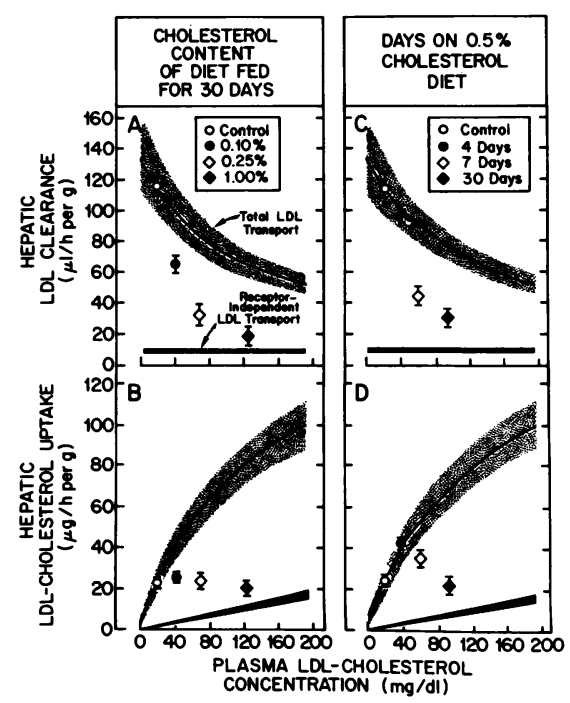

Figure 1. Hepatic LDL clearance and LDL-cholesterol uptake in animals fed varying amounts of cholesterol for $30 \mathrm{~d}(A$ and $B)$ or $0.5 \%$ cholesterol for varying periods of time $(C$ and $D)$. The shaded areas represent the kinetic curves for total (stippled) and receptor-independent (hatched) LDL transport (mean values $\pm 2 \mathrm{SD}$ ) in the liver of normal animals with a constant receptor number $\left(J^{m}\right)$. The individual points superimposed on these kinetic curves represent the means \pm 1 SEM for data obtained in six animals. 


\section{Results}

We first examined the effect of adding cholesterol alone to the diet and the results of these studies are summarized in Table $\mathbf{I}$. Control animals were fed the low cholesterol, low triglyceride rodent diet and experimental animals were fed the same diet that was either enriched with varying amounts of cholesterol $(0.1,0.25$, or $1 \%)$ and fed for $30 \mathrm{~d}$, or that was enriched with $0.5 \%$ cholesterol and fed for varying periods of time $(4,7$, or 30 d). Although not shown, the rate of weight gain was essentially identical in all groups of animals. Liver weight, however, progressively increased as increasing amounts of dietary cholesterol were fed or when the same amount of dietary cholesterol was administered for longer periods of time (column 1). Similarly, the hepatic cholesteryl ester content, which was $0.8 \mathrm{mg} / \mathrm{g}$ in control animals, increased as a function of both the amount of cholesterol in the diet and the time on the diet (column 2). As shown in columns 3 and 4, dietary cholesterol produced a dose-dependent and time-dependent suppression in rates of hepatic LDL clearance and reciprocal elevations in plasma LDL-cholesterol concentrations. Although the data are not shown, the rate of methyl-hLDL clearance (receptor-independent transport) equaled $11 \pm 3 \mu \mathrm{l} / \mathrm{h}$ per $\mathrm{g}$ in control animals and was not significantly altered by cholesterol feeding.

Because the circulating levels of LDL-cholesterol increased in all animals fed cholesterol, these changes in LDL clearance could not be equated directly with down-regulation of receptor-dependent LDL transport since saturation of this receptor system could, at least partially, explain these changes. To distinguish between these two possibilities, the kinetics of receptor-dependent and receptor-independent LDL transport in the liver of normal hamsters were defined over the range of LDLcholesterol levels seen in the cholesterol fed animals. This was accomplished by measuring rates of hepatic LDL clearance in control hamsters whose plasma LDL-cholesterol levels were acutely raised and maintained at values ranging from 25 to 200 $\mathrm{mg} / \mathrm{dl}$ by adding varying amounts of unlabeled homologous LDL to the primed-continuous infusions of radiolabeled LDL (13). These studies were performed using both homologous LDL (total LDL transport) and methyl-hLDL (receptor-independent transport). The data were analyzed using least-squares nonlinear regression analyses (13) and the best-fit curves \pm 2 $\mathrm{SD}$ are presented in Fig. 1. The upper panels show the rela- tionship between rates of total (stippled areas) and receptor-independent (hatched areas) hepatic LDL clearance and plasma LDL-cholesterol concentrations under circumstances where the LDL receptor number, i.e., $J^{\mathrm{m}}$ for the receptor-dependent system (13), was constant. These same data are presented in the lower panel as total and receptor-independent LDL-cholesterol uptake (micrograms per hour per gram). In both cases, the area between the two curves represents the receptor-dependent component of LDL transport.

The observed rates of LDL transport in the cholesterol-fed animals are superimposed upon these kinetic curves for LDL transport in control animals. As seen in $A$, rates of hepatic LDL clearance in animals fed cholesterol for $30 \mathrm{~d}$ fell significantly below those rates that would be expected in normal animals at similar plasma LDL-cholesterol concentrations. It can be calculated from this analysis that receptor-dependent LDL clearance per gram of liver was suppressed by $\sim 45,70$, and $85 \%$ in the animals fed $0.1,0.25$, and $1.0 \%$ cholesterol, respectively. Since the suppression of hepatic LDL clearance was accompanied by a rise in plasma LDL levels, the actual mass of LDL-cholesterol taken up per hour per gram of liver in these same animals remained remarkably constant at $\sim 25 \mu \mathrm{g}$ (B). However, whereas $>90 \%$ of LDL transport was receptor dependent in the control animals, receptor-independent mechanisms became increasingly important in the cholesterol-fed animals and actually accounted for most of the LDLcholesterol uptake that took place in the animals fed $1.0 \%$ cholesterol. The time dependency of these changes is illustrated in $C$ and $D$. When animals were fed a $0.5 \%$ cholesterol diet for only $4 \mathrm{~d}$, the plasma LDL-cholesterol concentration doubled, the LDL clearance rate decreased slightly, but there was no change in the absolute rate of receptor-dependent transport $(C)$ indicating that this initial rise in the plasma LDL-cholesterol concentration was due entirely to increased LDL-cholesterol production. As a consequence, the amount of LDL-cholesterol taken up by the liver at $4 \mathrm{~d}$ was nearly doubled $(D)$. However, with longer periods of feeding there was progressive suppression of receptor-dependent LDL uptake to those values seen at $30 \mathrm{~d}$ of cholesterol feeding.

When the data in Fig. 1 are corrected for changes in liver weight (Table I), the effect of dietary cholesterol on whole liver LDL receptor activity can be determined and these values, along with the plasma LDL-cholesterol levels, are plotted in

Table I. Effect of Dietary Cholesterol on Hepatic Cholesteryl Ester Content, Cholesterol Synthesis, and LDL Transport, and on Plasma LDL-Cholesterol Concentrations

\begin{tabular}{|c|c|c|c|c|c|c|}
\hline $\begin{array}{l}\text { Cholesterol added to } \\
\text { control diet }\end{array}$ & Time on diet & Liver weight & $\begin{array}{l}\text { Hepatic cholesteryl } \\
\text { ester content }\end{array}$ & $\begin{array}{l}\text { Hepatic cholesterol } \\
\text { synthesis }\end{array}$ & $\begin{array}{l}\text { Hepatic LDL } \\
\text { clearance }\end{array}$ & $\begin{array}{l}\text { Plasma LDL-cholesterol } \\
\text { concentration }\end{array}$ \\
\hline$\%$ & $d$ & $g$ & $m g / g$ & nmol/h per $g$ & $\mu l / h$ per $g$ & $m g / d l$ \\
\hline 0.10 & 30 & $5.8 \pm 0.1$ & $11 \pm 1$ & $8 \pm 2$ & $65 \pm 4$ & $43 \pm 4$ \\
\hline 0.25 & 30 & $6.4 \pm 0.2$ & $26 \pm 1$ & $6 \pm 1$ & $32 \pm 2$ & $72 \pm 5$ \\
\hline 1.0 & 30 & $7.9 \pm 0.3$ & $88 \pm 6$ & $6 \pm 1$ & $18 \pm 2$ & $126 \pm 13$ \\
\hline 0.5 & 7 & $6.3 \pm 0.2$ & $27 \pm 2$ & $6 \pm 2$ & $46 \pm 4$ & $62 \pm 3$ \\
\hline 0.5 & 30 & $7.3 \pm 0.3$ & $48 \pm 4$ & $6 \pm 1$ & $28 \pm 3$ & $96 \pm 5$ \\
\hline
\end{tabular}

Groups of animals were fed diets enriched with $0.10,0.25$, or $1.0 \%$ cholesterol for $30 \mathrm{~d}$ or with diets containing $0.5 \%$ cholesterol for 4,7 , or $30 \mathrm{~d}$. Each value represents the mean \pm 1 SEM for data obtained in six animals. 

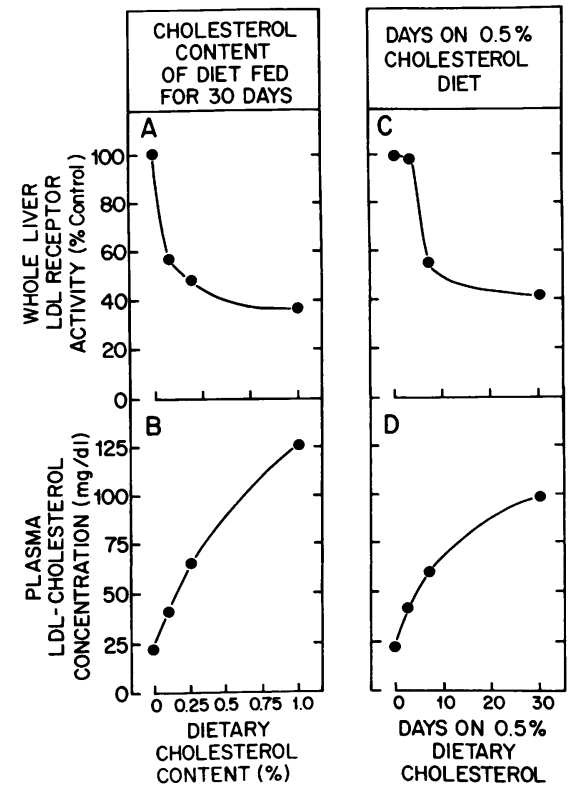

Figure 2. Whole liver receptor-dependent LDL clearance and plasma LDL-cholesterol concentrations in animals fed varying amounts of cholesterol for $30 \mathrm{~d}(A$ and $B)$ or $0.5 \%$ cholesterol for varying periods of time $(C$ and $D)$. Whole liver receptor-dependent LDL clearance was obtained by multiplying the percent reduction in receptor-dependent LDL clearance per gram of tissue by the whole liver weight and then expressing the values as percentages of the control value.

Fig. 2 as a function of the content of cholesterol in the diet $(A$ and $B$ ) or the number of days that the $0.5 \%$ cholesterol diet was fed $(C$ and $D)$. Since cholesterol increased liver weights as a function of the dose and time on the diet, the suppression of hepatic LDL receptor activity was somewhat less when expressed per whole liver than when expressed per gram of tissue.

In the second group of experiments we next examined the effect of dietary triglycerides alone on rates of hepatic LDL transport. In these experiments, hamsters were fed either the control ground rodent diet or the same diet enriched with $20 \%$ safflower oil, $20 \%$ olive oil, or $20 \%$ hydrogenated coconut oil for one month. Weight gain among the animals fed the various triglycerides was identical but $\sim 15 \%$ greater than seen in the control animals. As shown in Table II, the liver weights and hepatic cholesteryl ester contents were not affected by triglyceride feeding (columns 1 and 2). Rates of hepatic cholesterol synthesis, however, increased by approximately five-, three-, and twofold, respectively, in animals fed safflower oil, olive oil, and hydrogenated coconut oil. Rates of hepatic LDL clearance were not significantly altered by the triglyceride diets. Plasma LDL-cholesterol levels were only modestly affected by supplementing the diet with triglyceride alone. Safflower oil and olive oil reduced plasma LDL levels by 28 and $20 \%$, respectively, while hydrogenated coconut oil increased plasma LDL-cholesterol levels $64 \%$. The absolute magnitude of these changes, however, was very small compared to that seen when cholesterol was present in the diet.

The third series of experiments was undertaken to examine the interaction of dietary triglyceride and cholesterol in regulating hepatic LDL transport. Accordingly, hamsters were fed diets supplemented with $0.06,0.12$, or $0.24 \%$ cholesterol with and without safflower oil (20\%) or hydrogenated coconut oil $(20 \%)$ and the results of these studies are summarized in Table III. At all levels of dietary cholesterol, hepatic cholesteryl ester levels (column 2) were highest in animals fed cholesterol alone, intermediate when safflower oil was added and lowest when hydrogenated coconut oil was added. The hepatic cholesteryl ester content equaled $0.6 \mathrm{mg} / \mathrm{g}$ in control animals (column 2 ). In animals fed $0.06 \%$ cholesterol alone, the hepatic cholesteryl ester content equaled $7.8 \mathrm{mg} / \mathrm{g}$ but this content was significantly lower in those hamsters simultaneously given safflower oil $(2.6 \mathrm{mg} / \mathrm{g})$ or hydrogenated coconut oil $(1.4 \mathrm{mg} / \mathrm{g})$. Similarly, in those animals fed the 0.12 and $0.24 \%$ cholesterol diets, hepatic cholesteryl ester contents were highest in the animals fed only cholesterol, were lower in those animals fed safflower oil and were the lowest when the hamsters were given hydrogenated coconut oil. Rates of hepatic cholesterol synthesis equaled $44 \mathrm{nmol} / \mathrm{h}$ per $\mathrm{g}$ in control animals (column 3). On the $0.06 \%$ cholesterol diet, rates of synthesis were suppressed $\sim 80 \%$ but this suppression was largely reversed in the animals fed either safflower oil or hydrogenated coconut oil. Similarly, when fed $0.12 \%$ or $0.24 \%$ cholesterol, the suppression in hepatic sterol synthesis was greater in the absence of triglyceride than in the presence of these oils. The rate of hepatic LDL clearance equaled $117 \mu \mathrm{l} / \mathrm{h}$ per $\mathrm{g}$ in control animals and was progressively suppressed when cholesterol was added to the diet. However, at each of the three levels of cholesterol feeding, hepatic LDL clearance was actually increased by adding safflower oil to the diet and was strikingly suppressed by feeding hydrogenated coconut oil (column 4). These changes in hepatic LDL clearance were faithfully reflected by reciprocal changes in the circulating plasma LDL-cholesterol concentrations (column 5). Thus, at any level of cholesterol feeding, the

Table II. Effect of Dietary Triglyceride on Hepatic Cholesteryl Ester Content, Cholesterol Synthesis and LDL Transport, and on Plasma LDL-Cholesterol Concentrations

\begin{tabular}{|c|c|c|c|c|c|}
\hline $\begin{array}{l}\text { Triglyceride added to } \\
\text { control diet }\end{array}$ & Liver weight & $\begin{array}{l}\text { Hepatic cholesteryl } \\
\text { ester content }\end{array}$ & $\begin{array}{l}\text { Hepatic cholesterol } \\
\text { synthesis }\end{array}$ & $\begin{array}{l}\text { Hepatic LDL } \\
\text { clearance }\end{array}$ & $\begin{array}{l}\text { Plasma LDL-cholesterol } \\
\text { concentration }\end{array}$ \\
\hline & $g$ & $m g / g$ & nmol/h per $g$ & $\mu l / h$ per $g$ & $m g / d l$ \\
\hline Safflower oil & $5.5 \pm 0.3$ & $0.6 \pm 0.1$ & $160 \pm 10$ & $138 \pm 8$ & $18 \pm 2$ \\
\hline Olive oil & $5.6 \pm 0.3$ & $0.9 \pm 0.2$ & $106 \pm 7$ & $114 \pm 7$ & $20 \pm 3$ \\
\hline Coconut oil & $5.3 \pm 0.4$ & $0.7 \pm 0.1$ & $78 \pm 6$ & $116 \pm 7$ & $41 \pm 3$ \\
\hline
\end{tabular}

Groups of animals were fed diets enriched with $0.10,0.25$, or $1.0 \%$ cholesterol for $30 \mathrm{~d}$ or with diets containing $0.5 \%$ cholesterol for 4,7 , or $30 \mathrm{~d}$. Each value represents the mean \pm 1 SEM for data obtained in six animals. 
Table III. Effect of Dietary Triglyceride at Varying Dietary Cholesterol Levels on Hepatic Cholesteryl Ester Content, Cholesterol Synthesis, and LDL Transport, and on Plasma LDL-Cholesterol Concentrations

\begin{tabular}{|c|c|c|c|c|c|c|}
\hline $\begin{array}{l}\text { Cholesterol added to } \\
\text { control diet }\end{array}$ & $\begin{array}{l}\text { Triglyceride added to } \\
\text { control diet }\end{array}$ & Liver weight & $\begin{array}{l}\text { Hepatic cholesteryl } \\
\text { ester content }\end{array}$ & $\begin{array}{l}\text { Hepatic cholesterol } \\
\text { synthesis }\end{array}$ & $\begin{array}{l}\text { Hepatic LDL } \\
\text { clearance }\end{array}$ & $\begin{array}{l}\text { Plasma LDL-cholesterol } \\
\text { concentration }\end{array}$ \\
\hline$\%$ & & $g$ & $m g / g$ & nmol/h per $g$ & $\mu l / h$ per $g$ & $m g / d l$ \\
\hline \multirow[t]{2}{*}{0.06} & None & $5.3 \pm 0.2$ & $7.8 \pm 1$ & $9 \pm 1$ & $77 \pm 6$ & $40 \pm 3$ \\
\hline & Safflower oil & $5.4 \pm 0.2$ & $2.6 \pm 0.2$ & $36 \pm 3$ & $103 \pm 7$ & $32 \pm 2$ \\
\hline \multirow[t]{3}{*}{0.12} & None & $5.8 \pm 0.3$ & $13 \pm 1$ & $7 \pm 1$ & $50 \pm 4$ & $63 \pm 4$ \\
\hline & Safflower oil & $5.6 \pm 0.3$ & $10 \pm 1$ & $20 \pm 1$ & $54 \pm 4$ & $57 \pm 4$ \\
\hline & Coconut oil & $5.8 \pm 0.6$ & $6 \pm 1$ & $18 \pm 2$ & $17 \pm 2$ & $156 \pm 9$ \\
\hline \multirow[t]{3}{*}{0.24} & None & $6.5 \pm 0.5$ & $30 \pm 2$ & $7 \pm 1$ & $38 \pm 3$ & $86 \pm 7$ \\
\hline & Safflower oil & $6.6 \pm 0.4$ & $23 \pm 2$ & $12 \pm 1$ & $41 \pm 3$ & $71 \pm 5$ \\
\hline & Coconut oil & $6.2 \pm 0.6$ & $8 \pm 1$ & $10 \pm 2$ & $14 \pm 2$ & $198 \pm 12$ \\
\hline
\end{tabular}

Groups of animals were fed diets enriched with $0.06,0.12$, or $0.24 \%$ cholesterol either alone or in combination with $20 \%$ safflower oil or $20 \%$ hydrogenated coconut oil. All diets were fed for $30 \mathrm{~d}$. Each value represents the mean \pm 1 SEM for data obtained in six animals.

addition of safflower oil tended to lower the plasma LDL-cholesterol concentration while feeding the saturated hydrogenated coconut oil markedly increased these levels.

When the rates of hepatic LDL clearance shown in Table III were superimposed on the appropriate kinetic curves for LDL transport in normal hamsters, the percentage reduction in receptor-dependent LDL transport could be calculated and these values, in turn, could be corrected for the slight differences in liver size found in the various groups. In Fig. 3 are shown the mean changes in whole liver LDL receptor activity and plasma LDL-cholesterol concentrations as a function of

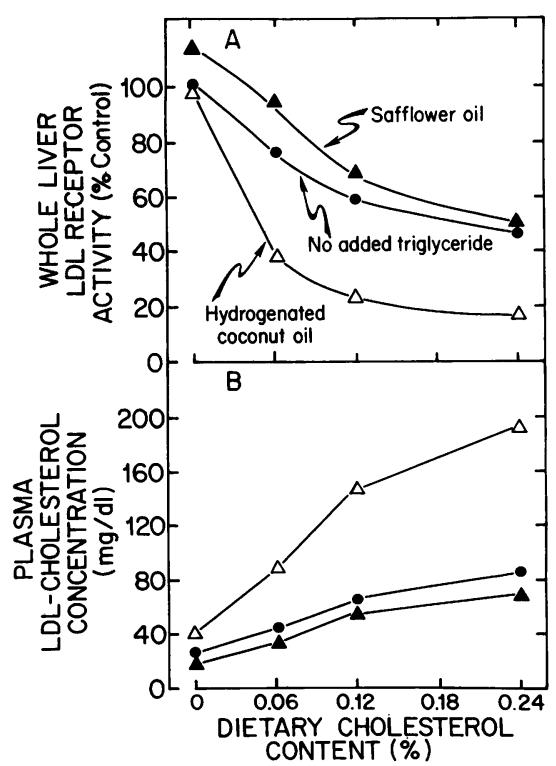

Figure 3. Whole liver receptor-dependent LDL clearance and plasma LDL-cholesterol concentration in animals fed diets enriched with $0.06,0.12$ or $0.24 \%$ cholesterol with and without $20 \%$ safflower oil or hydrogenated coconut oil. Whole liver receptor-dependent LDL clearance was obtained by multiplying the percentage reduction in receptor-dependent LDL clearance per $\mathrm{g}$ of tissue by the whole liver weights and is expressed as a percentage of the control value. the dietary cholesterol content in animals fed diets containing either no added triglyceride, safflower oil, or hydrogenated coconut oil. As is apparent, at each level of dietary cholesterol the suppression of whole liver receptor-dependent LDL transport was less in the presence of safflower oil and markedly greater in the presence of hydrogenated coconut oil. The most dramatic differences in whole liver receptor-dependent LDL clearance, however, occurred in animals fed the $0.06 \%$ cholesterol diet where safflower oil nearly abolished the suppressive effect of dietary cholesterol while hydrogenated coconut oil markedly augmented it. As shown in $B$, plasma LDL-cholesterol concentrations progressively rose with increasing amounts of dietary cholesterol; however, this rise was less in the presence of safflower oil but significantly greater in the presence of hydrogenated coconut oil.

Since the most dramatic modulation of hepatic LDL receptor activity by dietary triglyceride occurred in animals fed the $0.06 \%$ cholesterol diet and since this level of dietary cholesterol is similar to that of Western man $(\sim 150 \mathrm{mg}$ of cholesterol per $1,000 \mathrm{kcal}$ of diet), a fourth group of studies was undertaken to examine the time-course for the inhibition of hepatic LDL transport and its reversibility in animals fed $0.06 \%$ cholesterol for prolonged periods of time in the presence and absence of added safflower oil, olive oil, or hydrogenated coconut oil. Groups of animals were fed these diets for either 4 $\mathrm{d}$ or for 1,2 , or $4 \mathrm{mo}$. All animals were killed at $\sim 5 \mathrm{mo}$ of age. Total body weight gain was identical among the animals fed the three triglyceride-containing diets, but weight gain in these animals was somewhat greater than in control animals or in animals that received cholesterol alone. As shown in Table IV, hepatic cholesteryl ester levels increased with time in all animals fed the $0.06 \%$ cholesterol diet (column 2); however, the increase was greater in animals receiving olive oil and much less in animals receiving safflower oil or hydrogenated coconut oil so that after 4 mo the hepatic cholesteryl ester content was $12.7 \mathrm{mg} / \mathrm{g}$ in animals fed $0.06 \%$ cholesterol alone, but equaled $18,2.8$, and $1.9 \mathrm{mg} / \mathrm{g}$ when olive oil, safflower oil, or hydrogenated coconut oil, respectively, was added. Rates of hepatic LDL clearance fell in all animals fed the $0.06 \%$ cholesterol diet. The magnitude of this decline, however, was much less 
Table IV. Time-course for the Changes in Hepatic Cholesteryl Ester Content and LDL Clearance, and for Plasma LDL-Cholesterol Concentrations in Animals Fed 0.06\% Cholesterol Plus Safflower Oil, Olive Oil or Hydrogenated Coconut Oil for Prolonged Time Periods

\begin{tabular}{|c|c|c|c|c|c|c|}
\hline$\%$ & & & $g$ & $m g / g$ & $\mu l / h$ per $g$ & $m g / d l$ \\
\hline None & None & & $5.0 \pm 0.3$ & $0.7 \pm 0.1$ & $116 \pm 8$ & $25 \pm 2$ \\
\hline 0.06 & None & $\begin{array}{l}4 \mathrm{~d} \\
1 \mathrm{mo} \\
2 \mathrm{mo} \\
4 \mathrm{mo}\end{array}$ & $\begin{array}{l}4.9 \pm 0.3 \\
5.3 \pm 0.3 \\
5.8 \pm 0.2 \\
6.6 \pm 0.5\end{array}$ & $\begin{array}{c}2.1 \pm 0.1 \\
8.2 \pm 1 \\
9.6 \pm 1 \\
12.7 \pm 1\end{array}$ & $\begin{array}{r}100 \pm 7 \\
79 \pm 6 \\
61 \pm 6 \\
34 \pm 4\end{array}$ & $\begin{array}{l}29 \pm 2 \\
35 \pm 2 \\
40 \pm 3 \\
43 \pm 3\end{array}$ \\
\hline 0.06 & Safflower oil & $\begin{array}{l}4 \mathrm{~d} \\
1 \mathrm{mo} \\
2 \mathrm{mo} \\
4 \mathrm{mo}\end{array}$ & $\begin{array}{l}4.8 \pm 0.3 \\
5.3 \pm 0.2 \\
5.9 \pm 0.4 \\
6.8 \pm 0.4\end{array}$ & $\begin{array}{l}1.7 \pm 0.2 \\
2.8 \pm 0.2 \\
2.6 \pm 0.1 \\
2.8 \pm 0.3\end{array}$ & $\begin{array}{r}112 \pm 8 \\
103 \pm 8 \\
94 \pm 7 \\
81 \pm 7\end{array}$ & $\begin{array}{l}28 \pm 2 \\
30 \pm 3 \\
34 \pm 2 \\
35 \pm 2\end{array}$ \\
\hline 0.06 & Olive oil & $\begin{array}{l}4 \mathrm{~d} \\
1 \mathrm{mo} \\
2 \mathrm{mo} \\
4 \mathrm{mo}\end{array}$ & $\begin{array}{l}5.2 \pm 0.4 \\
5.3 \pm 0.4 \\
6.3 \pm 0.3 \\
7.4 \pm 0.5\end{array}$ & $\begin{array}{c}2.8 \pm 0.2 \\
9.9 \pm 1 \\
13.2 \pm 1 \\
18.0 \pm 2\end{array}$ & $\begin{array}{r}110 \pm 8 \\
102 \pm 6 \\
87 \pm 6 \\
74 \pm 7\end{array}$ & $\begin{array}{l}32 \pm 2 \\
38 \pm 3 \\
38 \pm 3 \\
39 \pm 3\end{array}$ \\
\hline 0.06 & Coconut oil & $\begin{array}{l}4 \mathrm{~d} \\
1 \mathrm{mo} \\
2 \mathrm{mo} \\
4 \mathrm{mo}\end{array}$ & $\begin{array}{l}5.2 \pm 0.3 \\
5.2 \pm 0.3 \\
6.0 \pm 0.2 \\
7.2 \pm 0.4\end{array}$ & $\begin{array}{l}1.0 \pm 0.1 \\
1.6 \pm 0.2 \\
1.6 \pm 0.2 \\
1.9 \pm 0.2\end{array}$ & $\begin{array}{l}86 \pm 6 \\
35 \pm 2 \\
30 \pm 2 \\
22 \pm 2\end{array}$ & $\begin{array}{l}45 \pm 3 \\
76 \pm 5 \\
87 \pm 6 \\
86 \pm 6\end{array}$ \\
\hline
\end{tabular}

Groups of animals were fed diets enriched with $0.06 \%$ cholesterol alone or in combination with $20 \%$ safflower oil, $20 \%$ olive oil, or $20 \%$ hydrogenated coconut oil for $4 \mathrm{~d}$ or for 1, 2, or $4 \mathrm{mo}$. Each value represents the mean \pm 1 SEM for data obtained in six animals.

when safflower oil or olive oil was added to the diet but was much more when hydrogenated coconut oil was administered (column 3). These changes in hepatic LDL clearance, in turn, were reflected by appropriate, reciprocal changes in plasma LDL-cholesterol levels (column 4).

When the hepatic LDL clearance rates shown in Table IV were compared to the appropriate kinetic curves and corrected for differences in liver weight, the percentage changes in hepatic LDL receptor activity were obtained. As shown in Fig. 4, in those animals raised for 4 mo on a diet containing $0.06 \%$ cholesterol alone there was a progressive decline in receptordependent LDL transport to $\sim 50 \%$ of the control value and a corresponding reciprocal rise in the plasma LDL-cholesterol concentration $(B)$. However, the addition of either safflower oil or olive oil to this cholesterol-containing diet almost totally abolished the suppressive effect of the dietary cholesterol on receptor-dependent LDL transport in the liver and largely blunted the rise in circulating LDL-cholesterol. In contrast, the addition of hydrogenated coconut oil to the diet markedly enhanced suppression of receptor-dependent hepatic LDL uptake and increased the plasma LDL-cholesterol concentrations to levels normally seen in adult man. Finally, after $4 \mathrm{mo}$, animals receiving each of the four dietary regimens were returned to control rodent diet containing neither added cholesterol nor triglyceride. As is also apparent in Fig. 4, at the end of $2 \mathrm{wk}$ the dramatic changes in receptor-dependent LDL transport and the plasma LDL-cholesterol levels had all reverted to the normal values found in the control animals. Thus, these diet-induced changes were rapidly reversible.

Since the hydrogenated coconut oil contained significant amounts of fatty acids of short and medium chain length, it was possible that the dramatic effect of this triglyceride on LDL metabolism was related more to the chain length of the fatty acids than to the degree of saturation. Therefore, the effect of pure tripalmitin on LDL metabolism was next studied, as shown in Fig. 5. Hamsters were fed the control ground rodent chow containing $0.06 \%$ cholesterol plus either olive oil $(20 \%)$, or olive oil $(12 \%)$ plus tripalmitin $(8 \%)$. As is apparent, when olive oil was partially replaced by tripalmitin, whole liver receptor-dependent LDL transport declined significantly and plasma LDL-cholesterol concentrations increased. Diets containing greater proportions of tripalmitin resulted in steator-

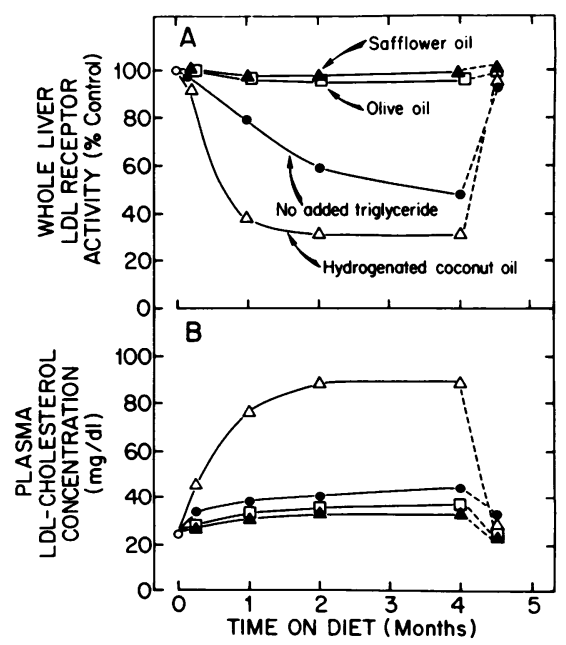

Figure 4. Whole liver receptor-dependent LDL clearance and plasma LDL-cholesterol concentrations in animals fed diets enriched with $0.06 \%$ cholesterol with or without $20 \%$ safflower oil, olive oil, or hydrogenated coconut oil as a function of time on the diet. The dashed lines represent the changes observed when animals were returned to the control low cholesterol, low triglyceride diet. 


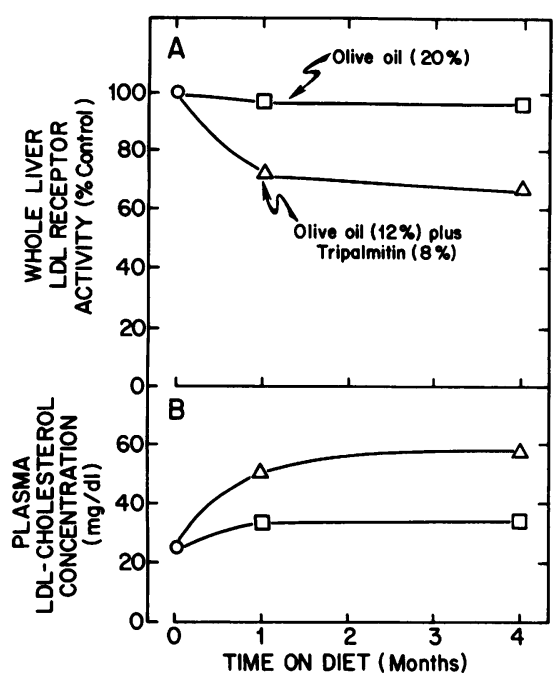

Figure 5. Whole liver receptor-dependent LDL clearance and plasma LDL-cholesterol concentrations in animals fed diets enriched with $0.06 \%$ cholesterol and either $20 \%$ olive oil or $12 \%$ olive oil plus $8 \%$ tripalmitin.

rhea and diminished weight gain and so it was not possible to study higher concentrations of dietary tripalmitin.

In a final study the mechanism by which saturated and polyunsaturated triglycerides modulated LDL metabolism was investigated by examining the effect of these triglycerides on the hepatic uptake of asialofetuin, a compound that is also removed from the plasma by a receptor-dependent pathway similar to that of the LDL receptor pathway $(29,30)$. As shown in Table V, the hepatic clearance of asialofetuin was approximately 40-fold higher than that of LDL. However, whole liver asialofetuin clearance was totally unaffected by feeding diets containing cholesterol and triglycerides (column 3). Thus, the receptor-dependent uptake of this compound continued at a constant rate under circumstances where the feeding of saturated and unsaturated dietary triglycerides resulted in marked alterations in receptor-dependent LDL transport into the liver.

\section{Discussion}

In man (14), as well as in the hamster (13), the steady-state concentration of plasma LDL-cholesterol is dictated by the balance between the rate of LDL entry into the plasma compartment (the LDL production rate, $J_{t}$ ) and the rate of LDL removal by the various tissues of the body through both receptor-independent $\left(J_{\mathrm{i}}\right)$ and receptor-dependent $\left(J_{\mathrm{d}}\right)$ mechanisms. In all species that have been examined thus far, $\sim 80 \%$ of the receptor-dependent LDL transport that is manifest in the whole animal is found in the liver (19-21). Furthermore, this hepatic receptor-dependent transport, but not the receptor-independent component, is subject to regulation by dietary additions such as cholesterol, triglyceride and bile acids $(15,31)$. Thus, it becomes of considerable importance to elucidate how the two major dietary lipids, i.e., cholesterol and triglyceride, interact to effect hepatic receptor-dependent LDL transport and, ultimately, the concentration of LDL-cholesterol in the plasma. Such information is particularly relevant to the situation in Western man where the intake of a diet high in lipids is associated with a progressive increase in plasma LDL-cholesterol levels and a high incidence of atherosclerotic complications $(32,33)$.

Using the hamster, four major conclusions were reached in these studies concerning the interrelationships that exist between the major dietary lipids, the functional levels of receptor-dependent LDL transport in the liver and the circulating concentrations of plasma LDL-cholesterol. First, feeding cholesterol alone caused a marked rise in the concentration of cholesteryl esters in the liver and suppression of both the rate of cholesterol synthesis and receptor-dependent LDL uptake. Second, saturated triglycerides augmented the suppressive effect of the cholesterol on hepatic LDL receptor activity and markedly elevated the circulating plasma LDL-cholesterol levels. In contrast, unsaturated triglycerides largely prevented the deleterious effect of dietary cholesterol on these parameters of hepatic metabolism. Third, feeding triglycerides disrupted the classical metabolic responses to cholesterol feeding that exist in the liver with respect to receptor activity, cholesteryl ester levels, and rates of cholesterol synthesis. Saturated triglycerides, for example, markedly lowered cholesteryl ester levels and increased rates of sterol synthesis under circumstances where receptor-dependent LDL transport was markedly suppressed. Finally, the detrimental effects of feeding cholesterol and saturated lipids on receptor-dependent LDL transport in the liver could be readily reversed by returning the experimental animal to a diet low in these lipids.

The first set of data provided by these studies was a detailed time-course for the effects of cholesterol feeding alone on hepatic LDL transport and circulating levels of LDL-cholesterol. Immediately after beginning cholesterol feeding, there was an apparent increase in the rate of LDL-cholesterol production

Table V. Effect of Dietary Cholesterol and Triglyceride on Hepatic Asialofetuin Transport

\begin{tabular}{|c|c|c|c|c|c|}
\hline $\begin{array}{l}\text { Cholesterol added to } \\
\text { control diet }\end{array}$ & $\begin{array}{l}\text { Triglyceride added to } \\
\text { control diet }\end{array}$ & Time on diets & $\begin{array}{l}\text { Hepatic asialofetuin } \\
\text { clearance }\end{array}$ & Liver weight & $\begin{array}{l}\text { Hepatic asialofetuin } \\
\text { clearance }\end{array}$ \\
\hline$\%$ & & mo & ml/hper $g$ & $g$ & ml/h per whole liver \\
\hline 0.06 & & 3 & $3.0 \pm 0.2$ & $6.5 \pm 0.4$ & $19.5 \pm 1$ \\
\hline 0.06 & Safflower oil & 1 & $4.3 \pm 0.2$ & $5.4 \pm 0.2$ & $23.0 \pm 2$ \\
\hline 0.06 & & 3 & $3.3 \pm 0.3$ & $6.7 \pm 0.4$ & $22.1 \pm 2$ \\
\hline
\end{tabular}

Groups of animals were fed diets enriched with $0.06 \%$ cholesterol alone or in combination with $20 \%$ safflower oil and $20 \%$ hydrogenated coconut oil for 1 or 3 mo. Each value represents the mean \pm 1 SEM for data obtained in six animals. 
such that at $4 \mathrm{~d}$ the plasma LDL-cholesterol concentration had nearly doubled yet there had been no change in hepatic LDL transport ( $D$, Fig. 1). As a consequence of this alteration, the amount of LDL-cholesterol taken up by the liver $4 \mathrm{~d}$ after commencing cholesterol feeding also nearly doubled. The liver cell apparently responded to this increased influx of sterol by reducing receptor-dependent LDL uptake until, at $30 \mathrm{~d}$, the absolute uptake of LDL-cholesterol had been returned to that level seen in the animals fed the control diet. Thus, $30 \mathrm{~d}$ after the initiation of cholesterol feeding, the rate of receptor-dependent LDL uptake by the liver had been adjusted so that the amount of LDL-cholesterol taken up remained constant at $\sim 25 \mu \mathrm{g} / \mathrm{h}$ per $\mathrm{g}$ regardless of the load of dietary cholesterol (B, Fig. 1). At the same time, there was also a marked increase in the level of cholesteryl esters in the liver cell and suppression of the rate of cholesterol synthesis (Table I). Thus, in this situation the liver of the hamster responded in the classical manner to increased cholesterol influx with suppression of cholesterol synthesis and receptor-dependent LDL transport and an increased level of cholesteryl ester formation. It should be noted that these responses were designed to maintain sterol homeostasis only in the liver cell. Unfortunately, these adjustments by the liver were detrimental to the animal as a whole in that the plasma LDL-cholesterol concentration necessarily increased.

The precise mechanism by which dietary sterol regulates the LDL receptor pathway is not known, although presumably long-term regulation is mediated by cholesterol, or some other product of mevalonate metabolism, at the transcriptional and/or translational level. It is also possible that excess dietary cholesterol could affect the LDL-receptor pathway by disturbing the cholesterol/phospholipid ratio and, perhaps, the fluidity of hepatic membranes. However, in these studies dietary cholesterol had little effect on the hepatic transport of asialofetuin, a glycoprotein that is taken up and degraded by the liver through a receptor-dependent pathway similar to that of LDL uptake $(29,30)$. Thus, these results are consistent with the view that enhanced uptake of dietary cholesterol leads to expansion of some putative intracellular, regulatory pool of sterol which, in turn, suppresses the synthesis (or increases the degradation) of the rate-limiting enzymes for cholesterol biosynthesis and the LDL receptor and expands the pool of cholesteryl esters $(34,35)$. Unless some other adaptive response occurs in other organs in the body, these changes in the liver will necessarily be associated with an increase in the circulating levels of LDL-cholesterol.

As demonstrated in the second group of studies, the addition of triglycerides to the diet markedly altered the metabolic response of the liver to cholesterol taken in simultaneously. At each level of dietary cholesterol, polyunsaturated triglycerides diminished, and saturated triglycerides markedly augmented, the effect of dietary cholesterol on hepatic receptor-dependent LDL transport. For example, whole-liver receptor-dependent LDL transport was suppressed $\sim 20 \%$ in animals fed the diet enriched with $0.06 \%$ cholesterol: however, this amount of cholesterol suppressed receptor-dependent LDL uptake by only $5 \%$ when given in the presence of dietary unsaturated oils but by nearly $70 \%$ when saturated triglycerides were administered to the animals. Similar differential effects were seen at other levels of cholesterol feeding although the percentage differences were less (Fig. 3). The data obtained in the animals fed $0.06 \%$ cholesterol are particularly relevant to the human situation since this load of cholesterol corresponds to the intake of $\sim 150 \mathrm{mg}$ of cholesterol per $1,000 \mathrm{kcal}$ of dietary intake. Thus, given this load of dietary cholesterol, the long-term effect of unsaturated lipids like safflower and olive oil is to block, in some manner, the deleterious effect of dietary cholesterol in suppressing receptor-dependent LDL transport in the liver so that the plasma LDL-cholesterol concentration remains at the low, essentially control value (Fig. 4). In contrast, the effect of saturated triglycerides is to greatly augment the suppressive effect of dietary sterol on receptor-dependent LDL transport leading, in turn, to a significant elevation in plasma LDL-cholesterol concentration. It is noteworthy that feeding this combination of small quantities of cholesterol $(0.06 \%)$ and larger amounts of saturated triglycerides caused the plasma LDLcholesterol level in the hamster to increase into the range of 80 to $100 \mathrm{mg} / \mathrm{dl}$, which is commonly encountered in Western man fed a similar diet (Fig. 4).

It is also important to recognize that these profound effects of saturated and unsaturated triglycerides were exerted independently when combinations of oils were fed as would occur, for example, in a mixed human diet. Thus, partial substitution of saturated triglycerides into a diet of unsaturated lipids clearly caused a predictable decrease in hepatic receptor-dependent LDL transport and a corresponding increase in the plasma LDL-cholesterol concentration (Fig. 5). In all of these studies commercial oils were used that contained a mixture of different medium and long chain-length fatty acids. It will be very important in future research to determine how the independent variables of fatty acid chain-length, numbers of double bonds and position of the double bonds specifically alter the characteristics of a given triglyceride to either alleviate or augment the effect of dietary cholesterol on hepatic LDL transport.

It is difficult to explain how dietary triglycerides so profoundly alter the hepatic response to dietary cholesterol although the third set of experimental data provides some insights into the underlying mechanisms. Previously published data have shown that after dietary cholesterol is delivered to the liver in the chylomicron remnant, a significant amount of the sterol is immediately esterified and stored in the liver cell as relatively inert, cholesteryl esters (36). At the same time, the regulatory pool(s) of sterol in the cell must be expanded since there is also invariably suppression of de novo cholesterol synthesis and, if these events are inadequate to meet the change in cholesterol homeostasis, suppression of LDL receptor activity (18).

Clearly, these classical responses to the uptake of dietary cholesterol are markedly altered by the simultaneous feeding of dietary triglycerides. For example, at each level of dietary cholesterol, hepatic cholesteryl ester levels were much lower in animals fed hydrogenated coconut oil than in animals fed safflower oil (Table III). Since the saturated fatty acids are poor substrates for the esterification reaction (37), it is conceivable that in this situation less intercellular cholesterol was sequestered in the inert ester pool, more free sterol entered the putative regulatory pool and there was a disproportionate suppression of LDL receptor synthesis. Alternatively, when safflower oil was fed a greater proportion of the dietary cholesterol load was sequestered into the ester pool, less free cholesterol entered the putative regulatory pool and there was derepression of receptor-dependent LDL transport.

This relatively simple explanation, however, does not account for the observation that safflower oil and hydrogenated coconut oil both reduced hepatic cholesteryl ester levels rela- 
tive to dietary cholesterol alone but had the opposite effect on hepatic LDL receptor activity (Fig. 3). Thus, while there is little doubt that the major effect of dietary triglycerides is to modify the metabolic response of the liver cell to dietary cholesterol, it is not entirely clear how this effect is mediated. Whether such modification is the result of the changes in the rate of cholesterol entry into the cholesteryl ester pool, alterations in the partitioning of free cholesterol between various membrane compartments or cytoplasmic carrier proteins or, even, changes in the fluidity of critical membranes within the cell remains to be elucidated.

There are two important implications of these experiments with respect to human nutrition. First, these data suggest that the detrimental effect of saturated triglycerides on LDL-cholesterol metabolism could be minimized if the intake of cholesterol could be reduced to essentially zero. While it is nearly impossible to accomplish this through dietary means, there are a number of new pharmacological agents that hold the promise of totally blocking sterol absorption and, so, effectively reducing the input of dietary cholesterol to near zero. Second, given the likelihood that Western diets will always contain at least several hundred milligrams of cholesterol each day, the alternative way in which to enhance hepatic receptor-dependent LDL transport is to be certain that the diet contains optimal amounts of those triglycerides that effectively block the deleterious effects of the dietary cholesterol. The experimental means are now available to work out the mechanism of action of these dietary fatty acids in protecting LDL transport and to determine the particular chemical configuration that maximizes this effect. Hopefully, when identified, such oils could be produced commercially and used in the production of a variety of food products.

\section{Acknowledgments}

The authors wish to thank Peggy Loessberg and Mark Ventura for their excellent technical assistance and Imogene Robison for preparing the manuscript.

This work was supported by U. S. Public Health Service Research grants HL-09610, AM-19329, and AM-01221 and by grants from the Moss Heart Fund and the Texas Affiliate of the American Heart Association (G155).

\section{References}

1. Kinsell, L. W., J. Partridge, L. Boling, S. Margen, and G. Michaels. 1952. Dietary modification of serum cholesterol and phospholipid levels. J. Clin. Endocrinol. Metab. 12:909-913.

2. Bronte-Stewart, B., A. Antonis, L. Eales, and J. F. Brock. 1956. Effects of feeding different fats on serum-cholesterol level. Lancet. i:521-526.

3. Beveridge, J. M. R., W. F. Connell, and G. A. Mayer. 1956. Dietary factors affecting the level of plasma cholesterol in humans: The role of fat. Can. J. Biochem. 34:441-455.

4. Ahrens, E. H., W. Insulll, R. Blomstrand, J. Hirsch, T. T. Tsaltas, and M. L. Peterson. 1957. The influence of dietary fats on serum-lipid levels in man. Lancet. i:943-953.

5. Connor, W. E., D. T. Witiak, D. B. Stone, and M. L. Armstrong. 1969. Cholesterol balance and fecal neutral steroid and bile acid excretion in normal men fed dietary fats of different fatty acid composition. J. Clin. Invest. 48:1363-1375.

6. Connor, W. E., D. B. Stone, and R. E. Hodges. 1964. The interrelated effects of dietary cholesterol and fat upon human serum lipid levels. J. Clin. Invest. 43:1691-1696.
7. Erickson, B. A., R. H. Coots, F. H. Mattson, and A. M. Kligman. 1964. The effect of partial hydrogenation of dietary fats, of the ratio of polyunsaturated to saturated fatty acids, and of dietary cholesterol upon plasma lipids in man. J. Clin. Invest. 43:2017-2025.

8. Becker, N., D. R. Illingworth, P. Alaupovic, W. E. Connor, and E. E. Sunberg. 1983. Effects of saturated, monounsaturateu, and $\omega-6$ polyunsaturated fatty acids on plasma lipids, lipoproteins, and apoproteins in humans. Am. J. Clin. Nutr. 37:355-360.

9. Goodnight, S. H., W. S. Harris, W. E. Connor, and D. R. Illingworth. 1982. Polyunsaturated fatty acids, hyperlipidemia, and thrombosis. Arteriosclerosis 2:87-113.

10. Shepherd, J., C. J. Packard, S. M. Grundy, D. Yeshumin, A. M. Gotto, and O. D. Taunton. 1980. Effects of saturated and polyunsaturated fat diets on the chemical composition and metabolism of low density lipoproteins in man. J. Lipid Res. 21:91-99.

11. Turner, J. D., N.-A. Le, and W. V. Brown. 1981. Effect of changing dietary fat saturation on low-density lipoprotein metabolism in man. Am. J. Physiol. 241:E57-E63.

12. Lewis, B. 1977. Plasma-lipoprotein interrelationship. Biochem. Soc. Trans. 5:589-601.

13. Spady, D. K., J. B. Meddings, and J. M. Dietschy. 1986. Kinetic constants for receptor-dependent and receptor-independent low density lipoprotein transport in the tissues of the rat and hamster. J. Clin. Invest. 77:1474-1481.

14. Meddings, J. B., and J. M. Dietschy. 1986. Regulation of plasma low density lipoprotein-cholesterol levels: Interpretation of LDL turnover data in man. Circulation. 74:805-814.

15. Spady, D. K., and J. M. Dietschy. 1985. Dietary saturated triacylglycerols suppress hepatic low density lipoprotein receptor activity in the hamster. Proc. Natl. Acad. Sci. USA. 82:4526-4530.

16. Bilheimer, D. W., Y. Watanabe, and T. Kita. 1982. Impaired receptor-mediated catabolism of low density lipoprotein in the WHHL rabbit, an animal model of familial hypercholesterolemia. Proc. Natl. Acad. Sci. USA. 79:3305-3309.

17. Kesaniemi, Y. A., J. L. Witztum, and U. P. Steinbrecher. 1983. Receptor-mediated catabolism of low density lipoprotein in man. Quantitation using glycosylated low density lipoprotein. J. Clin. Invest. 71:950-959.

18. Spady, D. K., S. D. Turley, and J. M. Dietschy. 1985. Rates of low density lipoprotein uptake and cholesterol synthesis are regulated independently in the liver. J. Lipid Res. 26:465-472.

19. Spady, D. K., D. W. Bilheimer, and J. M. Dietschy. 1983. Rates of receptor-dependent and -independent low density lipoprotein uptake in the hamster. Proc. Natl. Acad. Sci. USA. 80:3499-3503.

20. Spady, D. K., S. D. Turley, and J. M. Dietschy. 1985. Receptor-independent low density lipoprotein transport in the rat in vivo. Quantitation, characterization, and metabolic consequences. J. Clin. Invest. 76:1113-1122.

21. Spady, D. K., M. Huettinger, D. W. Bilheimer, and J. M. Dietschy. 1987. Role of receptor independent low density lipoprotein transport in the maintenance of tissue cholesterol balance in the normal and WHHL rabbit. J. Lipid Res. 28:32-41.

22. Glass, C. K., R. C. Pittman, G. A. Keller, and D. Steinberg. 1983. Tissue sites of degradation of apoprotein A-I in the rat. J. Biol. Chem. 344:7161-7167.

23. Bilheimer, D. W., S. Eisenberg, and R. I. Levy. 1972. The metabolism of very low density lipoprotein proteins. I. Preliminary in vitro and in vivo observations. Biochim. Biophys. Acta. 260:212-221.

24. Mahley, R. W., H. Weisgraber, G. W. Melchior, T. L. Innerarity, and K. S. Holcombe. 1980. Inhibition of receptor-mediated clearance of lysine and arginine-modified lipoproteins from the plasma of rats and monkeys. Proc. Natl. Acad. Sci. USA. 77:225-229.

25. Munford, R. S., J . M. Andersen, and J. M. Dietschy. 1981. Sites of tissue binding and uptake in vivo of bacterial lipopolysaccharide-high density lipoprotein complexes. Studies in the rat and squirrel monkey. J. Clin. Invest. 68:1503-1513.

26. Jeske, D. J., and J. M. Dietschy. 1980. Regulation of rates of cholesterol synthesis in vivo in the liver and carcass of the rat measured using $\left[{ }^{3} \mathrm{H}\right]$ water. J. Lipid Res. 21:364-376. 
27. Spady, D. K., and J. M. Dietschy. 1983. Sterol synthesis in vivo in 18 tissues of the squirrel monkey, guinea pig, rabbit, hamster, and rat. J. Lipid Res. 24:303-315.

28. Andersen, J. M., and J. M. Dietschy. 1978. Relative importance of high and low density lipoproteins in the regulation of cholesterol synthesis in the adrenal gland, ovary, and testis of the rat. J. Biol. Chem. 253:9024-9032.

29. Schwartz, A. L., S. E. Fridovich, and H. F. Lodish. 1982. Kinetics of internalization and recycling of the asialoglycoprotein receptor in a hepatoma cell line. J. Biol. Chem. 257:4230-4237.

30. Pardridge, W. M., A. J. Van Herle, R. T. Naruse, G. Fierer, and A. Costin. 1983. In vivo quantification of receptor-mediated uptake of asialoglycoproteins by rat liver. J. Biol. Chem. 258:990-994.

31. Spady, D. K., E. F. Stange, L. E. Bilhartz, and J. M. Dietschy. 1986. Bile acids regulate hepatic low density lipoprotein receptor activity in the hamster by altering cholesterol flux across the liver. Proc. Natl. Acad. Sci. USA. 83:1916-1920.

32. Grundy, S. M. 1984. Recommendations for the treatment of hyperlipidemia in adults. A joint statement of the Nutrition Commit- tee and the Council on Arteriosclerosis of the American Heart Association. Arteriosclerosis. 4:445A-468A.

33. 1985. Consensus Conference: Lowering blood cholesterol to prevent heart disease. JAMA (J. Am Med. Assoc.) 253:2080-2097.

34. Faust, J. R., K. L. Luskey, D. J. Chin, J. L. Goldstein, and M. S. Brown, 1982. Regulation of synthesis and degradation of 3-hydroxy3-methylglutaryl-coenzyme A reductase by low density lipoprotein and 25-hydroxycholesterol in UT-1 cells. Proc. Natl. Acad. Sci. USA 79:5205-5209.

35. Luskey, K. L., J. R. Faust, D. J. Chin, M. S. Brown, and J. L. Goldstein. 1983. Amplification of the gene for 3-hydroxy-3-methylglutaryl coenzyme A reductase, but not the 53-kDa protein, in UT-1 cells. J. Biol. Chem. 258:8462-8469.

36. Nervi, F. O., H. J. Weis, and J. M. Dietschy. 1975. The kinetic characteristics of inhibition of hepatic cholesterogenesis by lipoproteins of intestinal origin. J. Biol. Chem. 250:4145-4151.

37. Jones, A., and J. Glomset. 1985. Biosynthesis, function and metabolism of sterol esters. In Sterols and Bile Acids. H. Danielsson and J. Sjovall, editors, Elsevier Science Publishers B. V., Amsterdam, The Netherlands, 95-119. 